\title{
Visual outcome of congenital and developmental cataract surgery in Lumbini Eye Institute
}

\author{
Anjita Hirachan ${ }^{1}$, Kabindra Bajracharya ${ }^{2}$, Salma KC Rai ${ }^{3}$, Arjun Malla Bhari ${ }^{4}$, \\ Avinash Chandra ${ }^{5}$ \\ ${ }^{1}$ Ophthalmologist, ${ }^{2}$ Associate Professor and Pediatric Ophthalmologist, ${ }^{3}$ Professor and Consultant Pediatric \\ Ophthalmologist, ${ }^{4}$ Consultant Pediatric Ophthalmologist, Lumbini Eye Institute, Bhairahawa, Nepal, ${ }^{5}$ Associate \\ Professor and Consultant Ophthalmologist, Universal College of Medical Sciences, Bhairahawa, Nepal
}

\section{A B S TR A C T}

Background: Paediatric blindness presents as an enormous problem to developing countries in terms of human morbidity, economic loss and social burden. Aims and Objective: The objective of this study was to observe the visual outcome of congenital and developmental cataract surgery. Materials and Methods: This study was prospective, longitudinal and interventional. The patients aged $\leq 15$ years, diagnosed either congenital or developmental cataract and planned for cataract surgery were enrolled during March 2014 to February 2015 at Lumbini Eye Institute, Nepal. The patients underwent either: a) Lens aspiration + $\mathrm{PPC}+$ Anterior Vitrectomy; b) Lens aspiration + PPC + Anterior Vitrectomy + PCIOL; c) Lens Aspiration + PCIOL depending upon age of patient. The patients were examined after surgery day 1, day 2, after 2 weeks and after 6 weeks. Glasses were prescribed at 6 weeks from the date of surgery. Occlusion therapy was initiated in cases wherever necessary. Results: A total of 54 eyes of 43 children were included in the study. The sex ratio was 1.26 female per male with mean age of 3 years (SD \pm 2.16 ). In the verbal group, $61.1 \%$ (33 eyes) had final visual acuity (6/6-6/18). In the non verbal group, $16.7 \%$ (9 eyes) had final visual acuity of good fixation and follow. There was a statistically highly significant improvement in post surgical Best corrected visual acuity $(p<0.001)$. Conclusion: Good visual outcome after pediatric cataract surgery can be obtained if surgery is performed by skilled surgeon. The awareness of pediatric cataract, early diagnosis and timely intervention to surgical treatment, and postoperative management of residual uncorrected refractive error and amblyopia are important factors for the prevention of childhood blindness from cataract.

\section{Access this article online}

Website:

http://nepjol.info/index.php/AJMS DOI: 10.3126/ajms.v9i2.18780 E-ISSN: 2091-0576

P-ISSN: 2467-9100

Key words: Visual acuity, Congenital and developmental cataract, Cataract surgery, Refractive error correction, Amblyopia

\section{INTRODUCTION}

'Cataract' the opacification of lens is one of the leading causes of blindness in children. ${ }^{1}$ However it not only blurs the retinal image but also disrupts the development of visual pathways. Managing pediatric cataract remains a challenge: treatment is often difficult, tedious and requires dedicated team effort. ${ }^{2}$ Clinic attendance is often delayed and significant amblyopia is likely to develop before surgery can be performed to clear the visual axis. ${ }^{3}$
It has been estimated that there are 1.4 million blind children in the world, 1 million of whom live in Asia and 0.3 million in Africa. Each year almost half a million children go blind. A child becomes bilaterally blind every minute, primarily within developing nations. ${ }^{2}$

However, pediatric cataract blindness is an important cause of preventable blindness and it presents an enormous problem to the developing world like ours. It profoundly influences educational, employment, personal, and social 
prospects. ${ }^{4}$ Restoring the sight of one child blind from cataracts may be equivalent to restoring the sight of 10 elderly adults. ${ }^{5}$

The objective of this study was to observe the visual outcome after surgery of cataract in children.

\section{MATERIALS AND METHODS}

A prospective study was conducted at Lumbini Eye Institute over a period of one year from March 2014 to February 2015. All the patients of congenital and developmental cataract up to age of 15 years who were planned for cataract surgery were included in the study. After obtaining informed consent from either parent a detailed history including family history, antenatal, prenatal, drug history, history of other ocular and systemic diseases and history of consanguinity was recorded.

The exclusion criteria were patients $>15$ years, traumatic cataract, complicated cataract, patients undergoing only secondary IOL implantation.

A detail pre-anaesthetic check up was done by qualified anaesthesiologist to assess the feasibility of surgery. All the surgeries were performed by three qualified paediatric ophthalmologists of LEI under general anaesthesia (GA). Informed consent was obtained for all patients from the parents/guardian after discussion of the risks, benefits and postoperative care.

In every visit, a detailed examination of the anterior and posterior segment and the possible complications were evaluated. The complications were managed accordingly. Visual acuity was assessed using standard protocol at each follow up. Postoperatively, the refractive status of the children was assessed by retinoscopy after surgery and repeated at each visit thereafter. Likewise amblyopia management was done by either patching. Patients were provided with optical corrections for any residual refractive errors 6 weeks after surgery, near glasses were prescribed whenever required. Data were entered in SPSS version 20 and results were interpreted in frequency and percentages. Ethical approval was obtained from institutional academic committee.

\section{RESULTS}

In this study the mean age of patients was $3 \mathrm{yr}( \pm 2.16 \mathrm{yrs}$ SD). There were 9 patients in the age group 1-5 years. There were 23 patients in the age group 6-10 years and 11 patients in the age group $>10$ years (Table 1 ). There were $19(44.2 \%)$ males and $24(55.8 \%)$ females included in the study (Figure 1). The ratio of male to female was 1: 1.26.
There were 37 cases of bilateral cataract and 6 cases were unilateral (Figure 2). The most common type of the cataract were Lamellar cataract $24(44.4 \%)$ and total cataract $23(42.6 \%)$ followed by Posterior subcapsular 6 (11.1\%). The others variant $(1.9 \%)$ included mixed cataracts and one anterior subcapsular cataract.

Most of the patients 39 eyes (72.2\%) underwent (Lens Aspiration + Posterior chamber Intraocular Lens) followed by (Lens Aspiration + Primary Posterior Capsulorrhexis + Anterior vitrectomy + Posterior chamber Intraocular lens) in 14 eyes $(25.9 \%)$ and (Lens Aspiration + Primary Posterior Capsulotomy + Anterior Vitrectomy) in 1 eye $(1.9 \%)$. In the verbal group, $61.1 \%$ (33 eyes) had final visual acuity (6/6-6/18). In the non verbal group, $16.7 \%$ (9 eyes) had final visual acuity of good fixation and follow (Table 2).

In contrary, if we considered all those eyes which were assessable by quantification of visual acuity $(\mathrm{n}=42)$, there was better outcome in post surgical BCVA compared to pre surgical BCVA but it was not statistically significant $(p=0.54)$.

Considering, improvement in individual eye and comparing pre and post surgical BCVA for that particular eye, there was a statistically significant improvement in pre surgical and post surgical BCVA $(p<0.001)$ (Table 3 ).

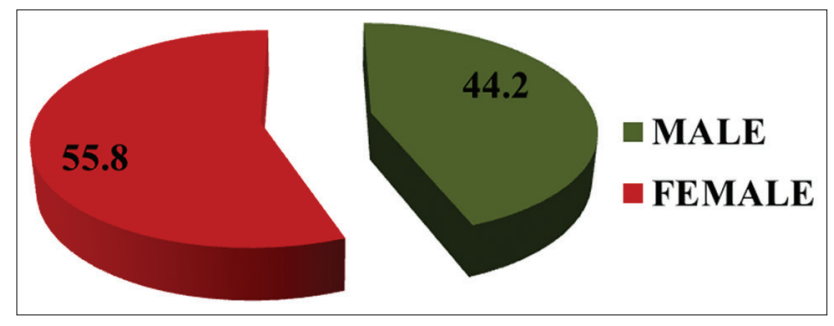

Figure 1: Gender distribution. $(n=43)$

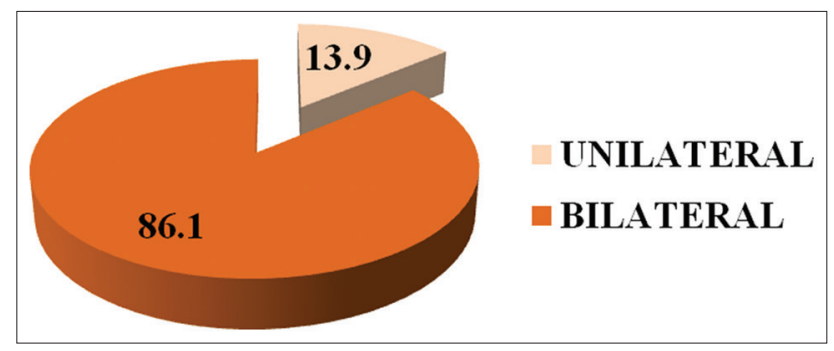

Figure 2: Frequency of laterality of cataract

\begin{tabular}{lcc}
\multicolumn{2}{l}{ Table 1: Age distribution } \\
\hline Age group & Number of patients & $\begin{array}{c}\text { Mean age } \pm \text { Standard } \\
\text { deviation }\end{array}$ \\
\hline $1-5$ & 9 & $3 \pm 2.16$ \\
$6-10$ & 23 & \\
$>10$ & 11 & \\
Total & 43 & \\
\hline
\end{tabular}




\section{Table 2: Final postoperative BCVA (At the end of 6 wks)}

\begin{tabular}{lcccccc}
\hline BCVA & $\mathbf{6 / 6 - 6 / 1 8}$ & $<6 / 18-6 / 60$ & $<6 / 60-3 / 60$ & $<3 / 60-P L$ & F \& F & Poor F \& F \\
\hline Number of eyes & 33 & 5 & 3 & 4 & 9 & 0 \\
\hline BCVA=Best Corrected Visual Acuity & & & & & &
\end{tabular}

\section{Table 3: Comparison between pre and post-surgery improvement in BCVA}

\begin{tabular}{lccccc} 
BCVA_group & \multicolumn{3}{c}{ Total } & P Value \\
\cline { 2 - 4 } & Improved & Stationary & Deteriorated & \\
\hline $6 / 6-6 / 18$ & 0 & $2(66.7)$ & $1(33.3)$ & 3 & $<0.001$ \\
$<6 / 18-6 / 60$ & $10(100)$ & 0 & 0 & 10 & 12 \\
$<6 / 60-3 / 60$ & $12(100)$ & 0 & 0 & 17 & 7 \\
$<3 / 60-$ PL & $15(88.2)$ & $2(11.8)$ & 0 & 5 & \\
Good F and F & $7(100)$ & 0 & 0 & 54 & \\
Poor F and F & $5(100)$ & 0 & 1 & 0 & \\
Total & 49 & 4 & & & \\
\hline
\end{tabular}

\section{DISCUSSION}

Visually impaired children have higher morbidity and mortality rates. Moreover, in developing countries they face a death of social service for their needs. However, predicting the refractive outcome is one of the main remaining challenges for the long-term care of children after cataract surgery. ${ }^{6}$ In early unilateral and bilateral cataracts, good prognosis for visual acuity and binocular vision depends on early diagnosis and surgery before the development of abnormal foveolar function.

The mean age of surgery was 3 years with $\mathrm{SD} \pm 2.16$. This is higher than what is reported in developed countries. However, it is comparable to reports from developing world and within Nepal where the age of presentation is still delayed. ${ }^{1,7}$ The main reason behind this delayed presentation is due to lack of awareness in the Nepalese community including primary health care workers and general physicians. Another important factor behind late presentation might be due to Nepal's topography as mentioned by Shrestha UD. ${ }^{8}$

There were $(44.2 \%)$ males and females $(55.8 \%)$ in this study. There was an almost equal distribution between males and females. David Yorston et al in their study found the rate of cataract surgery higher in boys than girls. The preponderance of male patients is more likely the result of the greater value accorded to male children in traditional societies, rather than to an increased incidence of cataract in boys. ${ }^{9}$ Jagat Ram et al also showed higher male: female (2.65:1) ratio with better visual outcome in male group.

In this study, a total of $86.1 \%$ of patients had bilateral presentation and only $13.9 \%$ had unilateral cataract. Increased ratio of bilateral cataract has been observed by other researches as well, a ratio of 3:1 reported by Johar et al. ${ }^{10}$ In another study at TIO by Shrestha UD et al also showed $89(67.4 \%)$ unilateral and 43(32.6\%) bilateral; the possible reason might be due to inclusion of traumatic cataracts, which are most of the time unilateral. ${ }^{8}$

The commonest mode of presentation in this study was decreased vision in $70.4 \%$. Other modes of presentation were white pupillary reflex, strabismus, nystagmus. Five $(9.25 \%)$ of the patient presented with strabismus; it must be due to delayed presentation. In developing countries like Nepal, it would be good to screen pediatric age group, as we do surgical camps for the adult cataract.

The percentage of visually impaired was quiet high in this study $39(72.2 \%)$, likewise in non-verbal group a considerable percentage $10(18.5 \%)$ present with poor fixation and follow. This corresponds well with findings from other studies. P. Gogate et $\mathrm{a}^{11}$ found preoperative best corrected vision was <3/60 in $405(76.6 \%)$ eyes, Nathan G.et al showed pre-operative best corrected vision $3 / 60$ in $236(66.5 \%)$ eyes. More recent study by Wilson et al showed presenting visual acuity of $<20 / 2000$. Thus, there has been no drastic change in trend of paediatric cataract surgery in the developing world over the past decade.

The visual results were encouraging, $90.7 \%$ of patient in this study showed improved visual acuity after surgery. At the end of 6 weeks follow up, $73.3 \%$ of eyes had best corrected vision in the range (6/6-6/18) and 100\% had good preferential fixation. The proportion with good acuity after surgery was better. Overall, post surgery there was statistically significant improvement in vision in all the eyes. The possible reason of such a good outcome might be availability of better technologies, better anaesthetic facilities, paediatric friendly environment. 
The most common early post-operative complication encountered was presence of fibrin reaction only in eyes that had IOL implantation and occurred within 1-2 weeks of surgery. Those patients were treated with oral steroid accordingly. Similar findings were reported by other authors. ${ }^{12}$ Complications related to IOL implantation were few, possibly due to the use of biocompatible IOLs and in-the-bag implantation in most cases. Posterior capsule opacification (PCO) requiring secondary surgical membranectomy was seen in one eye.

Children that improved vision after surgery were given spectacles for distance and for near. The children suspected to have amblyopia were provided patching therapy.

\section{CONCLUSION}

Good visual outcome after pediatric cataract surgery can be obtained if surgery is performed by skilled surgeon. The awareness of pediatric cataract, early diagnosis and timely intervention to surgical treatment, and postoperative management of residual uncorrected refractive error and amblyopia are important factors for the prevention of childhood blindness from cataract.

\section{REFERENCES}

1. Adhikari S, Badhu BP, Bhatta NK, Jha CB, Baral N and Kumari N. Etiology and clinical profile of paediatric cataract in a tertiary care center of eastern nepal. J Nepal Med Assoc 2007;46(167):94-98.
2. Wilson ME, Pandey SK and Thakur J. Paediatric cataract blindness in the developing world: surgical techniques and intraocular lenses in the new millennium. $\mathrm{Br} \mathrm{J}$ Ophthalmol 2003;87:14-19.

3. Ecksteina M, Vijayalakshmia P, Gilbertb $\mathrm{C}$ and Fosterb A. Randomised clinical trial of lensectomy versus lens aspiration and primary capsulotomy for children with bilateral cataract in south India. Br J Ophthalmol 1999;83:524-529.

4. Rahi JS, Gilbert CE, Foster A and Minassain D. Measuring the burden of childhood blindness. $\mathrm{Br} J$ Ophthalmol 1999;83:387-388.

5. Thylefors B, Negrel AD, Pararajasegaram R and Dadzie KY. Global data on blindness. Bulletin of the World Health Organization 1995;73(1):115-121.

6. Sminia ML, de Faber JTHN, Doelwijt DJ, Wubbels RJ and TjonFo- Sang M. Axial eye length growth and final refractive outcome after unilateral paediatric cataract surgery $\mathrm{Br} \mathrm{J}$ Ophthalmol 2010;94:547-550.

7. Thakur J, Reddy H, Edward Wilson M, Paudyal G, Gurung R, Thapa S, et al. Paediatric cataract surgery in Nepal. J Cataract Refract Surg 2004;30:1629-1635.

8. Shrestha UD and Shrestha MK. Clinical Profile of Paediatric Cataract and Surgery in a Tertiary Eye Care Centre, Nepal J Nepal Paediatr Soc. 2012;32(1):14-18.

9. Yorston $\mathrm{D}$, Wood $\mathrm{M}$ and Foster $\mathrm{A}$. Results of cataract surgery in young children in east Africa. Br J Ophthalmol 2001;85:267-271.

10. Kaid Johar SR, Savalia NK, Vasavada AR and Gupta PD. Epidemiology based etiological study of pediatric cataracts in Western India. Indian J Med Sci 2004;58:115-121.

11. Gogate P, Khandekar R, Shrishrimal M, Dole K, Taras S, Kulkarni $\mathrm{S}$, et al. Delayed presentation of cataracts in children: are they worth operating upon? Ophthalmic Epidemiol 2010;17(1):25-33.

12. Khanna RC, Foster A, Krishnaiah S, Mehta MK and Gogate PM. Visual outcomes of bilateral congenital and developmental cataracts in young children in south India and causes of poor outcome Indian J Ophthalmol 2013;61:65-70.

\footnotetext{
Authors Contribution:

AH- Concept, design of the study, reviewed literature, collected data, manuscript preparation, editing and revision of the manuscript; KB- editing and revision of the manuscript; SKC- Editing; AMB- Review literature; AC- editing and revision of manuscript.

Orcid ID:

Dr. Anjita Hirachan - (1) http://orcid.org/0000-0001-7316-0302

Dr. Kabindra Bajracharya - (i) http://orcid.org/0000-0002-1742-9220

Dr. Salma KC Rai - (i) http://orcid.org/0000-0001-5559-1512

Dr. Arjun Malla Bhari - (1) http://orcid.org/0000-0003-2753-5155

Source of Support: Nil, Conflict of Interest: None declared.
} 